\title{
CLUSTER BRANDING: O CASO DO VALE DOS VINHEDOS CLUSTER BRANDING: THE CASE OF THE VALE DOS VINHEDOS
}

\section{Ana Cláudia Azevedo}

Doutoranda em Administração pela FEA-USP, Mestre em Administração pela FUMEC.

Data de recebimento: 09/08/2017

\section{Willerson Lucas de Campos Silva}

Data de aceite: 13/03/2018

Doutorando em Engenharia de Produção pela Universidade de São Paulo (POLI/USP). Mestrado em Administração (2015) pela Universidade Federal de Mato Grosso do Sul (UFMS).

\section{Cristina Espinheira Costa Pereira}

Professora do Programa de Mestrado Acadêmico em Administração da Universidade Paulista (UNIP).

\section{João Maurício Gama Boaventura}

Professor da FEA-USP e também atua como Professor na Fundação Instituto de Administração - FIA, na Fundação Escola Comércio Álvares - FECAP e no Programa de Mestrado em Administração da Universidade Paulista - UNIP.

\section{RESUMO}

O objetivo deste estudo foi investigar como o cluster branding é gerenciado e percebido pelos atores envolvidos no cluster. Operacionalmente realizou-se um estudo de caso instrumental em uma região do cluster vitivinícola da Serra Gaúcha, denominada Vale dos Vinhedos. A coleta de dados foi realizada por entrevistas semiestruturadas e análise documental. Os resultados demonstram que há o desenvolvimento de atividades ligadas à construção do brand fortemente vinculadas às características da região; a entidade Aprovale é a responsável por estratégias para alcançar e gerir o cluster branding; os atores do cluster percebem positivamente a existência do brand e seus benefícios, tais como a união sob um propósito comum e uma identidade partilhada pelas empresas locais. A contribuição deste estudo consiste em uma discussão integrando áreas de investigação complementares, quais sejam: as literaturas sobre aglomerações produtivas e marketing de lugar, direcionando pesquisas futuras que se desenvolvam na perspectiva do desenvolvimento regional.

Palavras-Chave: Cluster. Branding. Território. Denominação de origem. Indicação geográfica.

\section{ABSTRACT}

The objective of this study was to investigate how cluster branding is managed and perceived by the actors involved in the cluster. Operationally, an instrumental case study was carried out in a region of the Serra Gaúcha wine cluster, denominated Vale dos Vinhedos. Data collection was performed through semi-structured interviews and documentary analysis. The results show that the development of activities related to the construction of the brand strongly linked to the characteristics of the region; The Aprovale entity is responsible for strategies to achieve and manage cluster branding; The actors of the cluster positively perceive the existence of the brand and its benefits, such as union under a common purpose and an identity shared by local companies. The contribution of this study consists of a discussion integrating complementary research areas, such as literature on productive agglomerations and site marketing, directing future research that develops from the perspective of regional development.

Keywords: Cluster. Branding. Territory. Denomination of origin. Geographical Indication.

João Maurício Gama Boaventura jboaventura@usp.br 


\section{INTRODUÇÃO}

Clusters são agrupamentos de empresas e instituições correlatas, geograficamente concentradas e vinculadas por elementos comuns e complementares que competem, mas também cooperam entre si (PORTER, 1999). Empresas co-localizadas alcançam ganhos coletivos que ampliam o seu poder de competição em relação àquelas que atuam isoladas ou menos aglomeradas (SKOKAN; ZOTYKOVÁ, 2015). Em função disso, clusters são amplamente reconhecidos em função de seu potencial competitivo.

Entretanto, para que um cluster de fato alcance sua competitividade, é necessário um alinhamento estratégico, que coordene atividades, elementos e recursos de forma a alcançar melhores resultados (ZACCARELLI et al., 2008). É válido ressaltar que, entre as estratégias desenvolvidas para assegurar a competitividade de um cluster, deve-se dedicar atenção a fatores que ocasionem sua atratividade, explorando seus diferenciais. Nesse sentido, uma boa gestão de marketing (WANG; WANG, 2010), sobretudo no que diz respeito ao place branding, ou como será tratado neste estudo, marketing de lugar, pode ser um fator crítico para aumentar a competitividade de um cluster (GAGNÉ et al., 2010).

Frente ao exposto, a literatura sobre cluster e marketing de lugar apresenta um grande alinhamento, pois concorda que clusters são exemplos específicos de lugar que exigem uma gestão cuidadosa de brand (KASABOV; SUNDARAM, 2011, p. 03). Ainda segundo esses autores, embora já seAinda segundo esses autores, embora já se observem alguns sinais precoces de pensamento con- vergente acerca desses tópicos, há pouca evidência de esforços combinados para examinar clusters sob a ótica de marketing de lugar. Essa associação é recente e os estudos que a envolvem são bastante raros (VÄINÖLÄ, 2015), assim como os estudos envolvendo a literatura de marketing e clusters de forma geral (WANG; WANG, 2010).

Na fronteira dos trabalhos que se desdobram sobre essa perspectiva, encontram-se os de Andersson, Solitander e Ekman (2013), que empregam um novo conceito relativo à prática de branding em clusters denominado cluster branding. Esses autores definem cluster branding como a forma pela qual um cluster gerencia sua reputação e alcança uma posição distinta em função de sua identidade e do que produz de forma mais eficaz.

O brand de um cluster apresenta basicamente três funções principais: (i) reforçar a capacidade do cluster em atrair investimentos e mão de obra qualificada, (ii) integrar os atores do cluster sob um propósito, uma visão comum e uma identidade partilhada e (iii) auxiliar na complementação das atividades de marketing de empresas locais (LUNDEQUIST; POWER, 2002)"type" : "article-journal", "volume" : "10" \}, "uris" : [ "http://www.mendeley.com/documents/?uuid=e4b6d09f-a597-44f6-a410-d1e40f464c33" ] \} ], "mendeley" : \{ "formattedCitation" : "(LUNDEQUIST; POWER, 2002. Nesse sentido, de acordo com Charters e Michaux (2014), o brand do cluster pode ser mais competitivo que o brand de uma empresa individual.

Diante desse contexto, o objetivo deste estudo é investigar como o cluster branding é gerenciado e percebido pelos atores envolvidos no cluster. 
Para tanto, este trabalho apresenta três questões de pesquisa, quais sejam: (i) como ocorre a criação do cluster branding? (ii) Quais as ferramentas empregadas na gestão do cluster branding? E (iii) quais os benefícios provenientes do cluster branding na percepção dos atores do cluster?

Em termos operacionais, optou-se por observar esse fenômeno em uma região do cluster vitivinícola da Serra Gaúcha, denominada Vale dos Vinhedos, conduzindo-se assim um estudo de caso instrumental. Existe uma crescente conscientização sobre a necessidade de uma atualização para um posicionamento estratégico que explore melhor as novas oportunidades do mercado de vinho brasileiro, que deve ser considerado e analisado por seu grande potencial de expansão (WILK; FENSTERSEIFER, 2003).

Assim, para fins desta pesquisa, assumiu-se como premissa que o título de Vale dos Vinhedos atribuído à região pesquisada, assim como os selos de indicação geográfica alcançados pelas empresas desse aglomerado, indicam que a região possui evidências da existência de cluster branding.

Frente ao exposto, a contribuição deste estudo consiste em uma discussão integrando áreas de investigação complementares, como a literatura sobre aglomerações produtivas e marketing de lugar, possibilitando o direcionamento de pesquisas futuras que se desenvolvam na perspectiva do desenvolvimento regional. Além disso, espera-se fornecer uma contribuição gerencial aos atores do cluster estudado, que conforme Wilk e Fensteiseifer (2003) buscam sistematicamente maneiras de desenvolver suas potencialidades para alcançar uma melhor posição no mercado de vinhos.

\section{REVISÃO DE LITERATURA}

\subsection{CLUSTERS}

Porter (1998, p. 199) define clusters como concentrações geográficas de empresas interconectadas, fornecedores especializados, prestadores de serviços, empresas em setores relacionados e instituições associadas em campos específicos e correlatos, que competem, mas também cooperam entre si. Esses aglomerados muitas vezes são mais importantes que países ou regiões subnacionais quando se consideram o crescimento econômico e a prosperidade (KRUGMAN, 1991).

A dinâmica desses arranjos empresariais envolve ações conjuntas em áreas diversificadas, como: recursos humanos, pesquisa e desenvolvimento, marketing, internacionalização, além de outros, inserindo na agenda estratégica questões relevantes para a obtenção de vantagens competitivas (DI SERIO, 2007).Essa concentração fortalece as empresas justamente por questões de proximidade e de acesso, posto que aquelas que atuam em clusters alcançam ganhos coletivos que ampliam seu poder de competição em relação às que atuam isoladas (ZACCARELLI et al., 2008). Nesse sentido, esses aglomerados são reconhecidos por sua capacidade de gerar externalidades e complementariedades provenientes da eficiência coletiva (SPENCER et al., 2010).

Dentre os tipos de complementariedade mais importantes, Porter (2000) destaca as complementariedades de marketing, que envolvem eficiência na comercialização conjunta e melhoria na reputação do local, favorecendo a atração de compradores e fornecedores. 
Nessa perspectiva, pode-se considerar que a concentração geográfica permite que empresas inseridas em um cluster alinhem suas estratégias no estabelecimento de uma identidade coletiva, uma espécie de marca global que represente o cluster como um todo. Assim sendo, a perspectiva de trabalhar o brand do cluster vai ao encontro à proposta de visão sistêmica da entidade supra-organizacional, reforçando a posição de que o todo é maior do que a soma das partes (ZACCARELLI et al., 2008). De acordo com Andersson, Solitander e Ekman (2013), o branding do cluster está diretamente ligado ao fortalecimento da atratividade e ao desenvolvimento econômico do aglomerado a longo prazo e, portanto, seu estabelecimento e manutenção são de grande relevância.

O marketing de lugar aplicado a regiões, a locais específicos (place branding) e aos clusters propriamente ditos (cluster branding) é descrito com maiores detalhes nos tópicos seguintes.

\subsection{MARKETING DE LUGAR}

Na concepção de Anholt (2004), place branding ou marketing de lugar, como é conhecido pelas pesquisas nacionais, é definido como a aplicação de estratégia de marca e outras técnicas de marketing para o desenvolvimento econômico e sociopolítico de vilas, cidades, regiões e países. Em complemento, Ocke e Ikeda (2014) afirmam que o marketing de lugar serve para diferenciar regiões da concorrência no que diz respeito ao desenvolvimento econômico e social.

Assim como o branding é aplicado a produtos e serviços, ele também pode ser associado a determinadas localizações (ANDERSSON; SOLI-
TANDER; EKMAN, 2013; HANNA; ROWLEY, 2015). Além disso, para Braun (2012), o marketing de lugar pode ser aplicado para a construção de uma imagem favorável e para uma diferenciação entre lugares competidores.

Já o brand de uma localidade específica objetiva promover uma imagem de qualidade e sustentabilidade do território ao qual se refere (LORENZINI; CALZATI; GIUDICI, 2011)applied to 79 touristic towns of the Marche Region (Italy. Trata-se de uma marca coletiva que pertence a determinada localização geográfica e que se relaciona a um produto ou serviço que não pode ser separado daquele lugar (CHARTERS et al., 2013, p. 1507). Conforme Bowen e Zapata (2009)we use the case of tequila to examine the potential for geographical indications (GIs, esse conceito une atores, histórias, organizações sociais e atividades.

Igualmente, a consciência e a familiaridade de marcas são traços enfatizados por autores como Hankinson (2004), Kavaratzis e Ashworth (2005), Konecnik e Go (2008) e Klijn, Eshuise e Braun (2012), os quais defendem o incremento desses traços por meio da construção de um brand atrativo por atividades de marketing.

Anholt (2004), por sua vez, explica que o marketing de lugar pode abranger diferentes localidades geográficas, como países, cidades, regiões e comunidades. A diversidade de pesquisas sobre branding de lugar envolvem diferentes iniciativas e perspectivas, incluindo temas como country brand, territorial brand, place brand (CHARTERS; SPIELMANN, 2014), sendo a mais recente proposta que envolve a aplicação de brand aos clusters, denominada por Andersson, Solitander e Ekman (2013) de cluster branding. 


\subsection{CLUSTER BRANDING}

O conceito de cluster branding se refere à forma como um cluster gerencia sua reputação e atinge uma posição distinta, com base em sua identidade e no que ele realiza de modo mais eficaz (ANDERSSON; SOLITANDER; EKMAN, 2013). Para Kasabov e Sundaram (2011), essa abordagem é relativamente recente e há uma escassez de trabalhos que promovam uma apreciação dos cluster como place brands.

Seguindo essa linha de pesquisas, Andersson, Solitander e Ekman (2013) se propuseram a descrever um processo viável de como clusters podem criar uma estratégia para uma gestão de marca efetiva. A partir de seus estudos, esses autores desenvolveram um modelo que representa as fases que devem ser incluídas em um cluster que marca o processo, conforme a Figura 1.

Figura 1 - O processo de gestão do cluster brand.

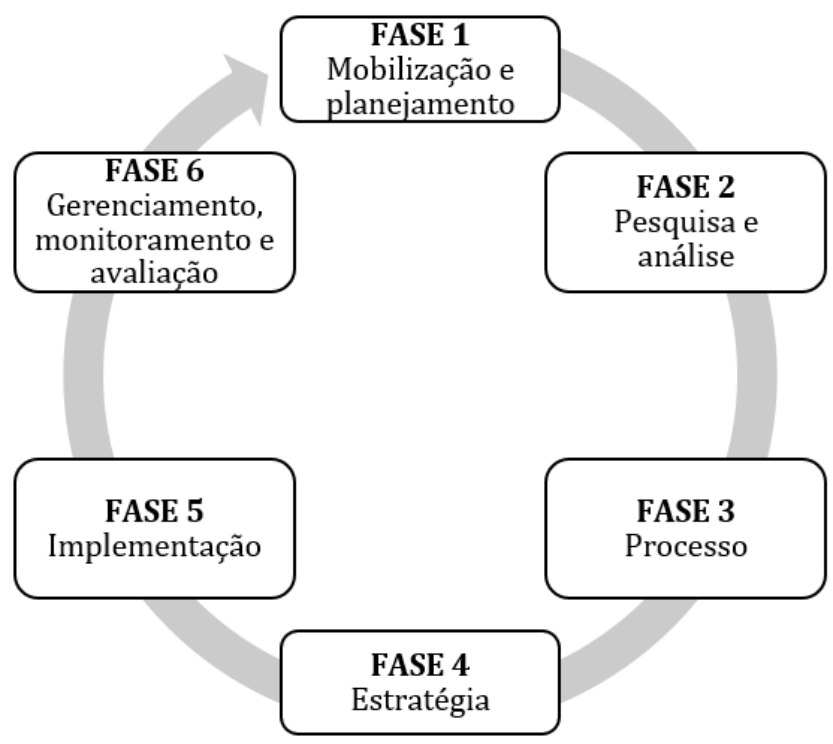

Fonte: baseado em Andersson, Solitander e Ekman (2013)

De forma mais específica, a fase 1 , de Mobilização e Planejamento, visa à mobilização e à construção de interesse e participação. É nessa fase ainda que são desenvolvidas a infraestrutura e a estrutura de gestão para o processo. Na fase 2, de Pesquisa e Análise, são prospectadas noções básicas sobre a identidade e a imagem da marca, bem como seus pontos fortes. Na fase 3, o Processo, é formada a plataforma de branding em um processo inclusivo. Na fase 4, Estratégia, decide-se sobre o núcleo de estratégia de branding. A fase 5 , Implementação, é de colocar os planos em ação. A última fase - Gestão, Acompanhamento e Avaliação - assegura o sucesso do processo, além de se garantir que as promessas do branding sejam cumpridas, avaliadas e afinadas.

A partir dos estudos de Charters e Spielmann (2014), emergiram quatro pré-requisitos para o alcance de um brand aplicado a localidades efetivo, são eles: (1) um brand manager eficaz e sensível, característica também ressaltada por Schamel (2006); (2) a disposição para a cooperação entre empresas concorrentes, no intuito de manter a marca territorial; (3) a existência de uma história comum, que ofereça um enfoque coletivo para as empresas individuais e; (4) o engajamento local.

Nessa perspectiva, Väinölä (2015) também delimita os processos de cluster branding em quatro fases, sendo elas: (1) justificativa para a existência e atração de membros; (2) identificação da marca/ identidade; (3) construção da credibilidade e criação de consciência e (4) gestão da imagem do brand.

As propostas desses autores convergem no entendimento de que o cluster branding possui uma trajetória específica de edificação, passando pela mobilização e a intensão de se estabelecer o brand e demandando uma organização estratégica que possa gerenciá-lo, um engajamento das partes envolvidas e uma gestão eficiente do brand efetiva- 
mente consolidado para que ele não pereça. Diante dessas definições, sintetiza-se a proposição deste estudo voltada para a compreensão das estratégias de brand no ambiente dos clusters:

P1: Para compreender a estratégia de cluster branding é preciso analisá-la sob três dimensões distintas: (i) origem, (ii) gestão/manutenção e (iii) externalidades.

Por origem, devem-se analisar todos os aspectos envolvidos na criação do brand do cluster, envolvendo características econômicas, sociais e culturais do aglomerado em questão; a análise de gestão deve se concentrar em ações realizadas para garantir o fortalecimento e a consolidação do cluster branding. E, por fim, é preciso identificar e analisar as externalidades provenientes do cluster branding para os atores do cluster, no intuito de analisar se elas são efetivas na promoção de ganhos para as partes.

\section{PROCEDIMENTOS DE INVESTIGAÇÃO E ANÁLISE}

Para este estudo, desenvolveu-se uma pesquisa de natureza qualitativa por uma abordagem exploratória (COLLINS; HUSSEY, 2005). Como orientação metodológica, seguiu-se a proposta do estudo de caso instrumental (STAKE, 2000), implementada em uma sub-região do cluster vitivinícola da Serra Gaúcha, denominada Vale dos Vinhedos, localizada no entorno dos municípios de Bento Gonçalves, Monte Belo do Sul e Garibaldi, todos no Rio Grande do Sul.

A coleta de dados foi realizada em fontes primárias e secundárias. Para a coleta dos dados primários aplicou-se a técnica de entrevista semiestruturada durante o mês de julho de 2016 . Foram realizadas cinco entrevistas, sendo quatro com representantes de vinícolas associadas à Aprovale e uma com um representante da própria Aprovale, conforme Quadro 1. Os roteiros utilizados nas entrevistas constam nos Apêndices A e B.

Quadro 1 - Perfil dos Entrevistados

\begin{tabular}{|c|c|c|c|}
\hline \multicolumn{1}{|c|}{ ID } & Gênero & Vinculação & Cargo \\
\hline E1 & Masculino & Aprovale & Administradora \\
\hline E2 & Feminino & Vinícola & Proprietário \\
\hline E3 & Masculino & Vinícola & Proprietário \\
\hline E4 & Masculino & Vinícola & Proprietário \\
\hline E5 & Masculino & Vinícola & \\
\hline
\end{tabular}

Fonte: elaborado pelos autores

No que tange às fontes secundárias, recorreu-se a material proveniente de sites institucionais das vinícolas, associações de classes e institutos de pesquisas, além de relatórios, materiais publicitários, vídeo documentários e pesquisas acadêmicas envolvendo o Vale dos Vinhedos - RS, todos disponibilizados em ambientes virtuais.
Os dados qualitativos gerados pelas entrevistas e pelos documentos em estudo foram reduzidos e segmentados em metacategorias para tratamento analítico, com inspiração na proposta de análise textual de Flores (1994). Diante da compilação dos dados primários e secundários, constituiu-se um corpus de análise com informações relativas 
ao Vale dos Vinhedos. Em primeira análise, esses materiais foram reduzidos a informações diretamente vinculadas ao objeto de estudo. Posteriormente, partiu-se para a busca de elementos que se enquadrassem nas categorias de análise emergentes da revisão de literatura. Nesse sentido, as categorias apresentadas na Figura 2 contribuem para a compreensão do significado da cluster branding.

Figura 2 - Categorias para análise de Cluster Branding

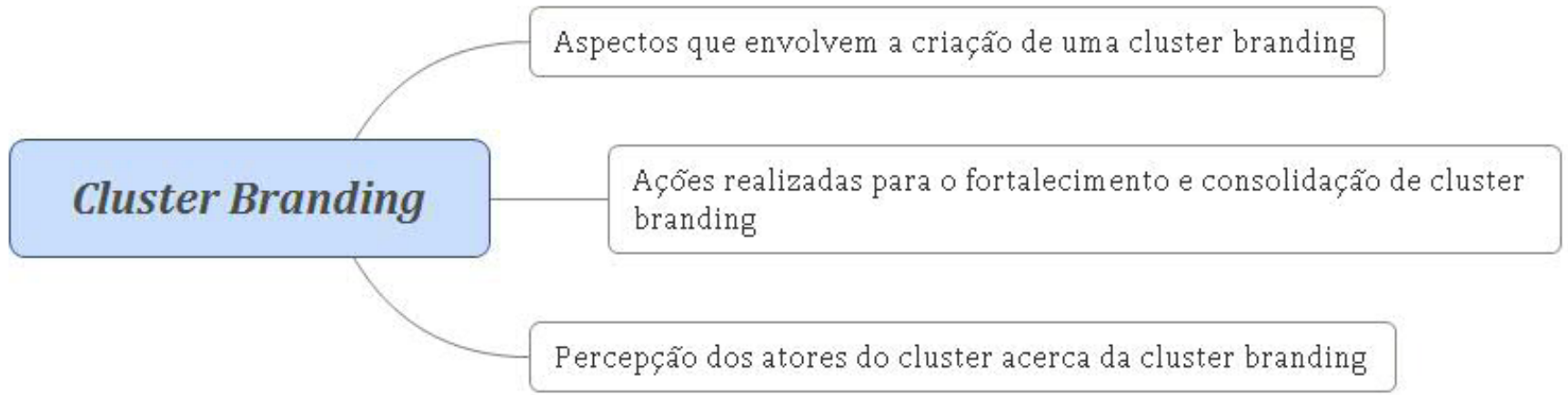

Fonte: elaborado pelos autores

Após distribuir os dados catalogados entre as categorias definidas, iniciou-se uma análise aprofundada desenvolvendo significados e associações relativas ao fenômeno de cluster branding. As categorias e suas subcategorias são apresentadas nas seções a seguir.

\section{ANÁLISE E DISCUSSÃO DOS RESULTADOS}

\subsection{O VALE DOS VINHEDOS}

A evolução do negócio do vinho e da uva no sul do Brasil constitui simultaneamente um repositório da experiência trazida pelos imigrantes de seus países de origem e a expressão de sua capacidade de adaptação às condições topográficas adversas e a questões climáticas (WILK; FENSTERSEIFER, 2003). Ainda segundo os autores, a história do vinho brasileiro remonta à colonização portuguesa, no século $X V I$, embora seu desenvolvimento atual se deva principalmente à chegada dos imigrantes italianos, a partir de 1875.

Nesse contexto, o Vale dos Vinhedos surgiu oficialmente em 17 de agosto de 1990, quando essa região foi instituída como distrito do município de Bento Gonçalves - RS (VALDUGA, 2012). Localizado no cluster vitivinícola da Serra Gaúcha e inserido no encontro dos municípios de Bento Gonçalves, Garibaldi e Monte Belo do Sul, o Vale constituiu-se sob um legado deixado pelos imigrantes italianos (APROVALE, 2016). A escolha pelo nome Vale dos Vinhedos é decorrente de uma combinação entre as características geográficas e a atividade econômica predominante da região - a vitivinicultura (FLORES, 2007).

A representação e a gestão do Vale dos Vinhedos está a cargo da Associação dos Produtores de Vinhos Finos do Vale dos Vinhedos (APROVALE), que conta com 26 vinícolas associadas e 43 empreendimentos de apoio ao turismo, entre hotéis, 
pousadas, restaurantes, queijarias e ateliês de arte, artesanato e antiguidades (APROVALE, 2016). Desde a formação da Aprovale, em 1995, e da eleição de sua primeira diretoria, no ano de 1996, esta passou a ser a única representação de grupos sociais interessados na promoção do desenvolvimento da região dos Vinhedos (FLORES, 2007). Graças aos esforços canalizados pela Aprovale, os vinhos do Vale dos Vinhedos apresentam identidade, sendo os únicos no Brasil a deterem Denominação de Origem; a região também foi a primeira no país a ser reconhecida como Indicação Geográfica (EMBRAPA, 2013).

\subsection{ANÁLISE DAS CATEGORIAS}

\subsubsection{Aspectos que envolvem a criação de um cluster branding}

No documentário "Memórias do Vale dos Vinhedos" vê-se que a atividade vitivinícola, determinante da identidade do local e de sua denominação como Vale dos Vinhedos, é carregada de aspectos histórico-culturais e foi induzida basicamente pela imigração italiana. Ademais, características geográficas, econômicas e étnicas foram balizadoras da implantação do cultivo da uva e da produção do vinho e podem, portanto, representar dois aspectos intrínsecos à constituição do brand de uma região, quais sejam: identidade clara e personalidade definida, estando estas associadas também à simbologia e à personalidade (KONECNIK; GO, 2008).

O processo de criação da brand de um cluster demanda, inicialmente, comprometimento das partes interessadas e organização de uma estrutura de gestão que lidere o processo de cluster branding (ANDERSSON; SOLITANDER; EKMAN, 2013). Nesse sentido, observa-se que a constituição da Aprovale, em 1996, foi o primeiro passo dado pelos empreendimentos da região para fortalecer sua atuação e reconhecimento.

Com a instituição da Aprovale a identidade do território começou a ganhar contornos que foram sendo estabelecidos pelo conjunto das vinícolas participantes do projeto (FLORES, 2007). E, para fortalecer a identidade do Vale como uma área diferenciada de elaboração de vinhos de boa qualidade, a associação em nome de seus associados, trabalhou para alcançar os selos de Indicação Geográfica (IG). Essa organização envolve elementos de duas fases do processo de cluster branding propostos por Andersson, Solitander e Ekman (2013): a pesquisa analítica e o processo.

Em entrevista, o consultor técnico da Aprovale destaca que esses selos são de grande importância para valorizar as características de cada uma das diferentes regiões produtoras de vinho, sobretudo para singularizar e ressaltar a originalidade e os níveis de qualidade do produto. Isso corrobora as estratégias de marketing de lugar voltadas à diferenciação de um local por suas particularidades e potencialidades, tornando-o mais atrativo e competitivo.

Em sua fala, o entrevistado explica também que existem duas classificações que podem ser obtidas no intuito de diferenciar as regiões que atuam na "elaboração" do vinho: a Indicação de Procedência (IP) e a Denominação de Origem (D.O.). O técnico em Enologia que acompanhou passo a passo as atividades da Aprovale, atuando junto aos processos de certificação, esclareceu ainda que tais processos são muito criteriosos e requerem o atendimento de regulações rígidas. O selo IP Vale dos Vinhedos, por exemplo, só pode ser utilizado 
para vinhos finos que apresentem determinados padrões de qualidade e sejam produzidos no Vale dos Vinhedos, com uvas também originárias da própria região.

Assim, no que se pode compreender como a fase estratégica apontada por Andersson, Solitander e Ekman (2013), em novembro de 2002, o Vale dos Vinhedos foi reconhecido como a primeira região com indicação geográfica na modalidade Indicação de Procedência (IP) do Brasil. Após a articulação de muitos esforços e a ação conjunta liderada pela Aprovale, os produtores alcançaram, em setembro de 2012, junto ao INPI, a “Denominação de Origem", indicação mais valiosa e recebida apenas pelos vinhos mais famosos do mundo.

O Brasil já possui sua primeira Denominação de Origem (DO) de vinhos e espumantes, modalidade mais complexa e valiosa de uma Indicação Geográfica (IG). A luta por essa conquista foi encabeçada pela Associação dos Produtores de Vinhos Finos do Vale dos Vinhedos (Aprovale), criada em 1996. De lá para cá, o sonho da DO sempre acompanhou o trabalho da entidade, ganhando força em 2010, quando o pedido foi oficializado. Em setembro de 2012, o Instituto Nacional de Propriedade Industrial (INPI) deferiu o pedido de registro de DO para o Vale dos Vinhedos. A decisão foi publicada no Registro de Propriedade Industrial (RPI) 2175 (SOCIEDADE NACIONAL DA AGRICULTURA, 2015).

A instituição da Aprovale e a organização de seus associados para alcançarem os selos de indicação geográfica são claros indícios de ações para a promoção do desenvolvimento da região.
O foco da Aprovale é estabelecido em torno de estratégias que promovam a aproximação das vinícolas com o consumidor, relação em que estão incluídos o enoturismo e a diferenciação dos produtos locais a partir de suas especificidades e da associação da imagem do Vale dos Vinhedos a seus produtos (FLORES, 2007). Entre esses mecanismos, destacam-se novamente a Indicação de Procedência e a Denominação de Origem.

A assimilação de aspectos intrínsecos à cultura local associada ao nome Vale dos Vinhedos indica que foram considerados aspectos internos e externos ao cluster para a determinação dessa marca. A estratégia de alcançar os selos e a preocupação em mantê-los denota o cuidado com a imagem do cluster. A marca Vale dos Vinhedos tem vida e fala por si, seja na identificação da região ou na promoção de seus produtos a partir dos selos alcançados. Já a vigilância constante pelo padrão de qualidade e a reputação do Vale demonstram que há acompanhamento e uma gestão do brand exercida principalmente pela própria Aprovale.

Assim, em relação aos aspectos que envolvem a criação do brand do cluster e sua consequente gestão, observa-se a necessidade de se ter uma representação articulada e organizada para direcionar ações, desde a concepção e a apropriação de características locais inerentes à região até a formalização de processos que assegurem que essas características sejam formalmente reconhecidas e diferenciem o cluster por seus méritos.

Certos padrões institucionalizados são necessários para gerenciar e monitorar o cluster branding. Nesse sentido e em consonância com os dados levantados, acredita-se que a Aprovale vem desempenhando bem esse papel. 
Isso porque, assumindo-se que o brand do Vale dos Vinhedos consolidou-se a partir dos selos de indicação geográfica, pode-se percorrer a trajetória de instituição dessa denominação a par- tir da fundação da Aprovale, de modo que as etapas descritas nessa linha do tempo remetem a aspectos que envolveram a criação do cluster branding (Quadro 2).

Quadro 2 - Linha do tempo da Aprovale

\begin{tabular}{ll} 
ANO & AÇÃo \\
\hline 1995 & Fundação da Aprovale \\
\hline 1997 & Início do processo de busca da certificação \\
\hline 2002 & Obtenção do registro da Indicação Geográfica pelo INPI \\
\hline 2007 & Reconhecimento pelo Comitê de Gestão do Vinho da União Europeia \\
\hline 2007 & Início do processo em busca da Denominação de Origem \\
\hline 2010 & Modernização da logomarca e identidade visual Vale dos Vinhedos \\
\hline 2011 & Previsão de obtenção de registro da Denominação de Origem \\
\hline 2012 & Deferido pedido de registro de Denominação de Origem para o Vale dos Vinhedos \\
\hline 2012 & Reconhecido como Patrimônio Histórico e Cultural do Rio Grande do Sul \\
\hline
\end{tabular}

Fonte: Aprovale (2016)

No que se refere à manutenção do brand, desde 2012, a Aprovale intensificou seu trabalho de esclarecer e consolidar os conceitos de indicação geográfica, de indicação de procedência e de denominação de origem, que, por serem relativamente recentes no Brasil, ainda não são compreendidos pelo mercado consumidor (MASIEIRO, 2013).

\subsubsection{Ações realizadas para o fortalecimento e consolidação do cluster branding}

O crescimento e a consolidação do cluster branding passa pela construção da credibilidade da marca e pela criação da consciência em relação a essa marca, e, por conseguinte, pela manutenção da imagem construída (VÄINÖLÄ, 2015). Sob esse aspecto, para Charters e Spielmann (2014), a entidade gestora tem seu papel na promoção geral do produto territorial. No caso do Vale dos Vinhedos, a Aprovale atua como a gestora da marca e busca cumprir a missão de "[...] promover o desenvolvi- mento sustentável do Vale dos Vinhedos através do enoturismo, da integração entre os associados e a comunidade, e para fomentar a busca contínua pela excelência em produtos e serviços" (APROVA$L E$, 2016). Atualmente, a entidade tem participado de discussões que visam ao desenvolvimento e à promoção da região, como sobre a criação de uma comissão em prol das Indicações Geográficas Brasileiras e a favor de tornar o Vale dos Vinhedos a Zona Franca de Vinhos do Brasil (APROVALE, 2016).

De acordo com Schamel (2006), o papel do brand manager se mostra particularmente importante para produtos, como o vinho do Vale dos Vinhedos, que são baseados na origem, pois construir uma consciência externa a respeito da qualidade do produto é fundamental para que haja a solidificação do valor de sua origem. Esse suporte ao aprimoramento contínuo da qualidade do produto faz parte dos objetivos da entidade ao "[...] incentivar a busca contínua pela excelência dos produtos e serviços" (APROVALE, 2016). 
Especificamente em relação à proteção dos produtos que recebem a Indicação Geográfica, a Aprovale se propõe ao "[...] controle dos produtos protegidos pela Indicação Geográfica do Vale dos Vinhedos e a sua gestão".

No entanto, para Pike (2005), os brand managers não devem ter um controle direto sobre os fornecedores locais, de forma a fazer com que eles cumpram a promessa da marca, mas devem agir como supervisores, com vistas ao incremento da qualidade do produto para todos os produtores da região. Contudo, desde que o Vale dos Vinhedos foi reconhecido com a Indicação Geográfica, seus produtos estão sujeitos a regras e padrões (APROVALE, 2016).

Dessa forma, os brand managers atuam como agentes reguladores a fim de atingir um padrão mínimo de qualidade dos itens produzidos e na busca por preservar a reputação global da marca. Em consequência, esses parâmetros protegem aqueles produtores que atendem aos padrões daqueles que fabricam um produto de qualidade inferior. De acordo com Aprovale (2016), para fazer a fiscalização e o controle dos critérios previstos pelo regulamento da Indicação Geográfica do Vale dos Vinhedos e da Denominação de Origem, a entidade possui um Conselho Regulador, constituído por representantes das vinícolas associadas, órgãos de pesquisa e ensino, além de consumidores (APROVALE, 2015).

A cada safra as vinícolas enviam à Aprovale uma solicitação para que o Conselho avalie os produtos que elas desejam que sejam identificados com a D.O. A Aprovale recolhe amostras destes vinhos e eles passam por análises da documentação para verificar se os padrões de cultivo e de elaboração estão de acordo com as normas estabelecidas (APROVALE, 2015, p. 13).

A Aprovale define, pois, as regras que visam garantir a qualidade da produção, concedendo o certificado apenas aos produtos que atenderem aos padrões, como quantidade máxima de uvas que poderão ser cultivadas pelas parreiras, restrições à variedade da uva e também à forma de seu processamento na hora da elaboração dos vinhos (APROVALE, 2015). Além dessas regras, impõe-se que 100\% da uva deve ser procedente da área demarcada (APROVALE, 2016).

Também precisam ser aprovados nas análises físico-químicas e na avaliação sensorial, realizada pelo Comitê de Degustação, composto por técnicos da Embrapa, técnicos de associados da Aprovale e da Associação Brasileira de Enologia (APROVALE, 2015).

É estabelecido pela Aprovale também que os produtos engarrafados provenientes da D.O. devem ser identificados no rótulo principal e no contrarrótulo, conforme exemplifica a Figura 3. Segundo a associação (APROVALE, 2015), esses números são códigos usados para o controle da D.O. e assim podem identificar a origem do vinho que está sendo vendido. 
Figura 3 - Rótulo Frontal e Contrarrótulo
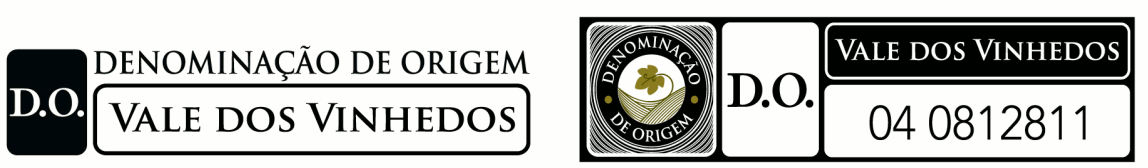

Fonte: EMBRAPA (2013)

A atuação dessa organização, junto às vinícolas e aos demais atores do Vale dos Vinhedos, é voltada para a garantia de um produto de qualidade e para a credibilidade dos produtos da região frente aos consumidores que consomem os vinhos do Vale dos Vinhedos. Sobre o tema, Charters e Spielmann (2014) orientam para a necessidade de cooperação para a manutenção de uma imagem de qualidade. Para tanto, encontros entre os membros participantes são essenciais para que haja discussões e sua inclusão no processo de construção e do fortalecimento da marca. Assim, reuniões, oficinas e workshops se constituem como boas ferramentas que permitem o debate e a troca de ideias (VÄINÖLÄ, 2015). Os atores se mostram ativos nesse aspecto, pois, recentemente, os empresários associados à Aprovale se reuniram para discutir a segurança no vale, os representantes do Vale dos Vinhedos também participaram da Oficina sobre a Experiência da Espanha no Registro e Controle de Indicações Geográficas e ainda, no ano de 2015, o Vale sediou o Fórum Intermunicipal de Planejamento Turístico e Econômico.

Outra ferramenta importante de fomento à integração entre os participantes do Vale é a participação conjunta em feiras e eventos do setor, uma das mais importantes e úteis atividades de branding (VÄINÖLÄ, 2015). O Vale dos Vinhedos se mostra ativo nesse quesito, estando presente ultimamente na Feira e Exposição de Produtos com Indicação
Geográfica em Fortaleza - CE, na Semana Internacional do Café e na I Summit Internacional de Inovação em Nutrição e Alimentos - Wine: Technology, Biotechnology and Health, dentre outros eventos (APROVALE, 2016).

Esses eventos são importantes para a construção da imagem, mostrando-se como uma boa ferramenta para promover a marca do cluster. Também se configuram como instrumentos para a manutenção da imagem construída em uma fase em que o cluster já ganhou consciência e credibilidade, tornando-se atrativo para os visitantes. Nesse cenário, o Vale dos Vinhedos sediou a primeira feira Tecnovitis, a qual pretendeu apresentar ao público os avanços da viticultura brasileira; também promoveu o Festival Emoções no Vale, o passeio ciclístico Pedal do Vinho e ainda traz os visitantes para participar da colheita das uvas, a Vindima (APROVALE, 2016).

Além dessas atividades, as vinícolas promovem ações que colocam os visitantes em contato direto com as uvas, como "Um dia de poda na Vinhos Larentis", ou ainda dá a oportunidade de eles aprenderem mais sobre vinhos, com minicursos e degustações, como em "Segredos do Mundo do Vinho", na Casa Valduga, e "Minicursos de degustação da Vinícola Miolo" (APROVALE, 2016).

Segundo Väinölä (2015), os websites e as mídias sociais são também importantes ferramentas para criar consciência no público e assim melho- 
rar a reputação global do cluster. Esses canais são, por muitas vezes, o principal meio de disseminação das informações do cluster. O autor ainda complementa, afirmando que a presença online do cluster é uma das chaves para a construção e a manutenção do brand.

O website do Vale dos Vinhedos (http:// www.valedosvinhedos.com.br), por exemplo, posiciona-se fortemente na promoção do enoturismo em consequência de seu forte apelo para conscientização e informação de seu público acerca de sua indicação geográfica, fator que traz diferenciação para seus produtos e atrações. O Vale dispõe de diferentes atrações turísticas que buscam fomentar o enoturismo na região, dentre elas: visitação às vinícolas, trilhas ecológicas, o Memorial do Vinho e Casa do Filó, Capitéis, a Capela das Neves e o Artesanato.

Destacados ainda por Väinölä (2015), os websites devem representar o cluster como um todo, mas com a responsabilidade também de apresentar todos os membros do cluster. A página do Vale cumpre esses dois pontos: primeiramente, ao se apresentar sob uma única marca, o Vale dos Vinhedos; e em um segundo momento, por reservar em sua página a sessão Empreendimentos, em que apresenta, não apenas as vinícolas, mas também hotéis e pousadas, opções gastronômicas e outros serviços. A apresentação desses empreendimentos introduz não apenas o nome e o contato do estabelecimento, mas busca mostrar como o local é parte integrante do contexto e da história do Vale.

Além do website, o Vale dos Vinhedos é presente em outras mídias sociais, como Facebook (www.facebook.com/valedosvinhedosoficial), blogs (www.valedosvinhedos.wordpress.com) e Insta- gram (@valedosvinhedosoficial). A utilização dessas mídias ratifica uma tendência de aproximação entre os clientes, os cidadãos e as comunidades, de forma a moldar a construção da marca para um modelo mais participativo (HANNA; ROWLEY, 2015).

Uma sessão no website do Vale é dedicada aos prêmios recebidos, tanto pelo Vale dos Vinhedos como pelas vinícolas que o compõem, podendo servir como importantes meio para a construção da credibilidade da região. Dentre essas premiações, podem-se citar: Chardonnay du Monde (2015), Vinalies Internacional (2015), Vinitaly 2015, Challenge du Vin 2015 (prêmios recebidos pelas vinícolas Casa Valduga e Gran Legado), CINVE (premiações dadas à Cooperativa Vinícola Aurora), dentre muitos outros prêmios e destaques (APROVALE, 2016).

Além disso, como o branding é um processo contínuo e a marca evolui ao longo do tempo, a manutenção do brand também deve ser contínua e se estender ao longo da vida do cluster. Essa manutenção passa pela preservação da imagem construída, pela conservação do interesse das audiências e pela avaliação contínua do processo de branding do cluster a fim de melhorar os resultados, caso necessário (ANDERSSON; SOLITANDER; EKMAN, 2013; VÄINÖLÄ, 2015).

Para essa manutenção do brand, as empresas do Vale dos Vinhedos utilizam as mesmas ações e ferramentas adotadas para sua construção. Também a atuação da entidade gestora da marca e a constante cooperação entre os atores são pontos importantes nesse processo (CHARTERS; SPIELMANN, 2014). Em relação à atuação da Aprovale, além das ações tomadas na construção do brand, devem almejar defender o nome da marca sempre que se tentar usá-la indevidamente. Esse posicionamento evita 
que empresas mal-intencionadas diluam o valor da marca, além de proteger o mercado consumidor de imitações, reforçando a verdadeira marca (OUWERSLOOT; ODEKERKEN-SCHRÖDER, 2008).

\subsubsection{Percepção dos atores do cluster sobre a cluster branding}

No intuito de compreender como os atores percebem de fato o cluster branding do Vale dos Vinhedos, buscou-se resgatar associações e benefícios percebidos por eles. Quando indagado sobre os benefícios de sua associação, sobretudo quanto aos selos de Indicação Geográfica, o representante da Aprovale esclareceu que, embora nem todas as vinícolas presentes no Vale dos Vinhedos estejam associadas à Aprovale (ele estima 32 empreendimentos no total, dos quais 26 fazem parte da entidade), todos os empreendimentos locais se beneficiam do enfoque que é dado ao Vale.

Sem dúvida todos ganham muito com o reconhecimento do Vale dos Vinhedos, mesmo algumas vinícolas que preferem seguir seus negócios sem a Aprovale se beneficiam da evidência do Vale, porque recebem compradores, muitos turistas, e ganham reputação também (E1).

O entrevistado argumenta que, antes da obtenção da Indicação Geográfica do Vale dos Vinhedos, em 2002, os produtores tinham dificuldades em comercializar suas marcas, a margem de lucro era muito baixa e ainda enfrentavam a concorrência das grandes vinícolas.

A partir do momento que nos unimos e começamos a realizar ações em grupo, como a cer- tificação, nós agregamos valor para o vinho da nossa região. O Brasil inteiro conhece o Vale dos Vinhedos, é fácil saber que aqui se elabora um bom vinho, isso é oficial. As pessoas sabem que temos uma qualidade particular, já temos algum reconhecimento internacional também (E1).

Na perspectiva das vinícolas esses os benefícios derivam da associação entre suas marcas e a marca do Vale dos Vinhedos. A fala do representante da Aprovale encontra endosso no depoimento dos entrevistados E2 e E5, proprietários de vinícolas do Vale.

[...] todos temos a consciência que qualquer ação desencadeada dentro do Vale dos Vinhedos acaba gerando renda para todos (E2).

Eu diria que o maior benefício é a região ser reconhecida, através disso aí a gente faz muitos negócios, até para fora do Brasil. Ter um nome de peso é importante demais nesse mercado de vinho. As pessoas têm que conhecer o lugar de onde esse vinho vem, tudo importa - a terra, a uva, a técnica, tudo (E5).

Esses entrevistados demonstram um sentimento de pertencimento ao Vale e enxergam o selo do Vale dos Vinhedos como uma marca coletiva de grande representatividade para as vinícolas.

Além de estarmos localizados em uma região enoturistíca reconhecida no mundo inteiro que acaba trazendo a porta de nossa vinícola inúmeros visitantes os produtos que contém a marca Vale dos Vinhedos acaba ganhando nome (E3). Fazer parte do Vale é um diferencial pelo con- 
ceito e credibilidade que o roteiro dá aos negócios daqui (E2).

Sem dúvida é bom para todo mundo, tem muita gente que fala que uns ganham mais do que os outros, mas no fim das contas ganhar todo mundo ganha só de falar que está no Vale dos Vinhedos (E4).

Sobre a percepção dos selos de indicação geográfica os entrevistados indicam que

É um atestado de qualidade, quando o cliente olha o rótulo do meu vinho e lê Vale dos Vinhedos ele passa a ter a certeza que tá comprando um produto de qualidade. Isso valoriza e eu acho que melhora as vendas (E3).

Só ganhamos nome a partir do momento que conquistamos a Indicação Geográfica Vale dos Vinhedos e logo após pela Denominação de Origem. Isso dá muita credibilidade a região e aos produtos que a gente elabora (E5).

Percebe-se por meio da fala dos entrevistados a associação entre os selos de identificação geográfica e os padrões de qualidade na elaboração dos vinhos como um forte apelo à construção e à solidificação da reputação do Vale. Nesse sentido, quando indagados se a marca do Vale dos Vinhedos é bem gerenciada, o entrevistado afirma:

Sim. Todos nós somos fiscais. Procurando zelar no uso do nome. A própria associação faz um trabalho continuo procurando conscientizar não só os associados, mas sim toda a comunidade da importância da marca. E os benefícios que ela traz a todos (E3).
Em relação à identificação com o Vale, os participantes pontuaram que se sentem representados pelo selo Vale dos Vinhedos e afirmam que tanto a marca do Vale quanto a sua própria, são igualmente importantes na condução dos negócios, estando inclusive muito associadas.

Sim, o Vale dos Vinhedos para mim é um conceito forte, mas só é o que é por causa dos envolvidos, todas vinícolas e outras empresas e associações que fazem parte dele, e que apoiam o roteiro sabe? (E4) A relação da nossa marca e o nome Vale dos Vinhedos é bem tranquila, todas as vinícolas dão ênfase a sua marca, mas ressaltam também a marca Vale dos Vinhedos, porque isso valoriza (E3).

Questionado sobre elementos que envolvem a identidade do Vale dos Vinhedos, outro entrevistado apontou uma resposta metafórica, pertinente às premissas de brand.

O conceito como região envolve solo, clima e homem. Como produto é o resultado destes três fatores (E3).

Uma incursão pelas páginas da Aprovale e das vinícolas do Vale dos Vinhedos permite a abstração de vários elementos comuns e uma comunicação muito alinhada, focada em transmitir as características histórico-culturais da região, valorizando a descendência italiana, a culinária e as características geográficas da região. Todos esses elementos são muito bem explorados em conexão direta com a atividade do enoturismo.

Um dos entrevistados acrescenta ainda que a Aprovale e seus associados buscam explorar a identidade da região e favorecer o enoturismo. 
[...] trabalhar bem as quatro estações do ano promovendo as belezas de cada estação buscando fazer com que os turistas se encantem com a estação presente e tenha a curiosidade de vivenciar as demais (E4).

No entanto, acrescenta que, embora a imagem e a identidade do Vale estejam sendo bem transmitidas (dentro dos recursos financeiros disponíveis), na opinião dele, a presença de maiores recursos, uma maior ênfase poderia ser dada a essa realidade.

Indagou-se também sobre suas participações em atividades vinculadas à divulgação do Vale, o que revelou novamente a associação de elementos particulares da região para favorecer a promoção do Vale, como é o caso da gastronomia e das características geográficas.

Por exemplo o Filó italiano, promovido por um hotel do Vale que disponibiliza espaço físico e serve alimentação [...] as vinícolas se fazem presente servindo seus vinhos aos participantes. Temos também passeio ciclístico com parada nas vinícolas, maratona do vinho, muita coisa (E5). As vinícolas realizam alguns eventos de degustação em conjunto (E2)

E, como nem todas as vinícolas do Vale são associadas à Aprovale, questionou-se como essa associação os diferenciava das demais vinícolas.

Trabalhando em conjunto somos mais fortes, contamos com a divulgação da associação, como empresa muitas vezes somos mencionados em revistas, jornais, televisão tudo isso de forma espontânea sem a necessidade de investimentos da empresa (E3).
Percebeu-se uma motivação muito pautada em externalidades de marketing, ou, como se pode assumir, do próprio cluster branding.

\section{CONSIDERAÇÕES FINAIS}

Este estudo teve como objetivo investigar como o cluster branding é gerenciado e percebido pelos atores de um cluster. Para tanto, procurou-se verificar como ocorre a criação do cluster branding, quais as ferramentas empregadas na gestão do cluster branding e quais os benefícios provenientes do cluster branding na percepção dos atores do cluster.

Analisando-se esses elementos no âmbito do Vale dos Vinhedos, percebeu-se que de fato há o desenvolvimento de atividades intensivas relacionadas à construção de uma imagem, uma marca, uma identidade que represente o local, recentemente externalizada por intermédio do selo de Denominação de Origem, alcançado em 2012. Na composição do cluster brand, são observados aspectos geográficos, históricos e culturais, diretamente vinculados à atividade econômica local - a vitivinicultura. Percebeu-se nos atores do cluster uma forte vinculação com as características da região, expressas em um latente senso de pertencimento.

A entidade gestora do aglomerado, a Aprovale, é também a principal responsável por orquestrar estratégias e ferramentas para o alcance e para a manutenção do cluster branding. Há indícios de uma atuação intensiva da entidade nesse propósito e os ganhos são percebidos no que se diz respeito à singularidade e à atratividade da região dos Vinhedos.

Assim como é proposto na literatura, os atores do cluster percebem positivamente a existência do branding e alcançam benefícios decorrentes de 
sua existência. Dentre eles, o principal é a notoriedade da região, que acaba por atrair público para os empreendimentos locais. Observa-se ainda que os ganhos alcançados envolvem unir os atores do cluster sob um propósito, uma visão comum e uma identidade partilhada, além da complementação das atividades de marketing das empresas locais.

Embora trate-se de uma literatura recente e ainda pouco explorada. observa-se que o desdobramento dos estudos sobre marketing de lugar conjugados às pesquisas sobre clusters, no que aqui denomina-se cluster branding, desenvolvem-se sobre proposições coerentes e alinhadas ao ambiente organizacional dos aglomerados.

Frente ao exposto, como os estudos envolvendo cluster branding são até certo ponto escassos, tratando-se de uma literatura ainda em consolidação, acredita-se que a contribuição deste estudo está em lançar mais luz sobre esse conceito emergente, destacando sobretudo sua capacidade de integrar duas áreas de investigação complementares, quais sejam, as literaturas sobre aglomera- ções produtivas e marketing de lugar, e direcionando pesquisas futuras que se desenvolvam na perspectiva do desenvolvimento regional.

Além disso, embora critérios para assegurar a robustez do estudo tenham sido adotados, em termos de triangulação de dados, a pesquisa apresenta algumas limitações. A primeira consiste na análise parcial do cluster da Serra Gaúcha, concentrada apenas na região do Vale dos Vinhedos. Outra limitação é o baixo número e variabilidade de atores entrevistados, além da realização de um estudo de caso único que dificulta a extrapolação de inferências aplicáveis a clusters de outras naturezas.

Como recomendação para estudos futuros, sugere-se aplicar este estudo em outras regiões do cluster vitivinícola da Serra Gaúcha, bem como em clusters de outros setores, para verificar a aplicabilidade e a dinâmica do cluster branding nos distintos aglomerados. Propõe-se também comparar um número maior de casos a fim de compreender o tópico com maior profundidade frente às distintas extrapolações.

\section{REFERÊNCIAS}

ANDERSSON, A. M.; SOLITANDER, A.; EKMAN, P. Cluster Branding and Marketing: a Handbook on Cluster Brand Management. Stockholm: Tendensor, 2013.

ANHOLT, S. Foreword. Place Branding and Public Diplomacy, v. 1, n. 1, p. 4-11, 2004.

\section{APROVALE. Manual da Indicação Geográfica do} Vale do Vinhedos. Bento Gonçalves: Aprovale, 2015. Disponível em: <http://www.valedosvinhedos.com.br/userfiles/file/cartilha_DO Aprovale.pdf>.
APROVALE. Vale dos Vinhedos: Aprovale - RS Brasil. Vale dos Vinhedos. 2016. Disponível em: <http://www.valedosvinhedos.com.br/vale/conteudo. php?view=44\&idpai=120\#null>. Acesso em: 5 jun. 2016.

BOWEN, S.; ZAPATA, A. V. Geographical indications, terroir, and socioeconomic and ecological sustainability: The case of tequila. Journal of Rural Studies, v. 25, n. 1, p. 108-119, 2009. Disponível em: <http://dx.doi.org/10.1016/j.jrurstud.2008.07.003> 


\section{REFERÊNCIAS}

BRAUN, E. Putting city branding into practice. Journal of Brand Management, v. 19, n. 4, p. 257-267, 2012.

CHARTERS, S. et al. Value in the territorial brand: the case of champagne. British Food Journal, v. 115, n. 10, p. 1505-1517, 2013.

CHARTERS, S.; MICHAUX, V. Strategies for wine territories and clusters: why focus on territorial governance and territorial branding? Journal of Wine Research, v. 25, n. 1, p. 1-4, 2014.

CHARTERS, S.; SPIELMANN, N. Characteristics of strong territorial brands: the case of champagne. Journal of Business Research, v. 67, n. 7, p. 1461-1467, 2014.

COLLINS, J.; HUSSEY, R. Pesquisa em Administração: um Guia Prático Para Alunos de Graduação e Pós-graduação. Porto Alegre: Bookman, 2005.

DI SERIO, L. C. Clusters Empresariais no Brasil: casos selecionados. São Paulo: Saraiva, 2007.

EMBRAPA. Denominação de Origem Vale dos Vinhedos. Embrapa Uva e Vinho. 2013. Disponível em: <http://www.cnpuv.embrapa.br/tecnologias/ ig/valedosvinhedos.html>. Acesso em: 10 jul. 2016.

FLORES, J. G. Análisis de datos cualitativos: aplicaciones a la investigación educativa. Barcelona: Promociones y Publicaciones Universitarias, 1994.
FLORES, M. X. Da solidariedade social ao individualismo: um estudo sobre o desenvolvimento do vale dos vinhedos na serra gaúcha. 2007. 311 f. Tese (Doutorado em Ciências Políticas)—Universidade Federal de Santa Catarina, Florianópolis, 2007

GAGNÉ, M. et al. Technology cluster evaluation and growth factors: literature review. Research Evaluation, v. 19, n. 2, p. 82-90, 2010.

HANKINSON, G. Relational network brands: towards a conceptual model of place brands. Journal of Vacation Marketing, v. 10, n. 2, p. 109-121, 2004.

HANNA, S.; ROWLEY, J. Towards a model of the Place Brand Web. Tourism Management, v. 48, n. July 2016, p. 100-112, 2015.

KASABOV, E.; SUNDARAM, U. A Stakeholder Approach to Branding Clusters: pointers to a Research Agenda. Regional Studies, p. 1-14, 2011.

KAVARATZIS, M.; ASHWORTH, G. J. City branding: an effective assertion of identity or a transitory marketing trick? Tijdschrift voor economische en sociale geografie, v. 96, n. 5, p. 506-514, 2005.

KLIJN, E.-H.; ESHUIS, J.; BRAUN, E. The Influence of Stakeholder Involvement on The Effectiveness of Place Branding. Public Management Review, v. 14, n. 4, p. 499-519, 2012.

KONECNIK, M.; GO, F. Tourism destination brand identity: the case of Slovenia. Journal of Brand Management, v. 15, n. 3, p. 177-189, 2008. 


\section{REFERÊNCIAS}

KRUGMAN, P. R. Geography and Trade. Cambridge: MIT press, 1991.

LORENZINI, E.; CALZATI, V.; GIUDICI, P. Territorial brands for tourism development: a statistical analysis on the Marche region. Annals of Tourism Research, v. 38, n. 2, p. 540-560, 2011. Disponível em: <http://dx.doi.org/10.1016/j.annals.2010.10.008>

LUNDEQUIST, P.; POWER, D. Putting Porter into practice? Practices of regional cluster building: evidence from Sweden. European Planning Studies, v. 10, n. 6, p. 685-704, 2002.

MASIEIRO, L. Indicação Geográfica: vale dos Vinhedos. A Lavoura, n. 696, p. 18-23, 2013. Disponível em: <http://www.youblisher.com/ p/642177-A-LAVOURA-696/>

OUWERSLOOT, H.; ODEKERKEN-SCHRÖDER， G. Who's who in brand communities-and why? European Journal of Marketing, v. 42, n. 5/6, p. 571-585, 2008.

PIKE, S. Tourism Destination Branding Complexity. Journal of Product \& Brand Management, v. 14, n. 4, p. 258-9, 2005.

PORTER, M. E. Clusters and the New Economics of Competition. Harvard Business Review, $n$. November, p. 77-90, 1998.

PORTER, M. E. Competição: estratégias competitivas essenciais. [s.I.] Gulf, 1999.
PORTER, M. E. Location, Competition, and Economic Development: Local Clusters in a Global Economy. Economic Development Quarterly, v. 14, n. 1, p. 15-34, 2000.

SCHAMEL, G. Geography versus brands in a global wine market. Agribusiness, v. 22, n. 3, p. 363-374, 2006.

SKOKAN, K.; ZOTYKOVÁ, L. Evaluation of business cluster performance during its lifecycle. Acta Universitatis Agriculturae et Silviculturae Mendelianae Brunensis, v. 62, n. 6, p. 1395-1405, 2015.

SOCIEDADE NACIONAL DA AGRICULTURA. Indicação Geográfica: vinhos do Vale dos Vinhedos. 2015. Disponível em: <http://sna.agr.br/indicacao-geografica-vinhos-do-vale-dos-vinhedos/>.

SPENCER, G. M. et al. Do clusters make a difference? Defining and assessing their economic performance. Regional Studies, v. 44, n. 6, p. 697-715, 2010.

STAKE, R. E. Case Studies. In: DENZIN, N.; LINCOLN, Y. (Ed.). The SAGE handbook of qualitative research. [s.I]: Sage, 2000. p. 435-455

VÄINÖLÄ, L.-E. As a Competitive Advantage. 2015. 82 f. Master's thesis (Cluster Brand as a Competitive Advantage Case: Airport Cluster Finland MSc program in Corporate Communication)_Aalto University, Espoo, 2015

VALDUGA, V. O desenvilvimento do enoturismo no Vale dos Vinhedos (RS/Brasil). Cultur, v. 6, n. 2, p. 127-143, 2012. 


\section{REFERÊNCIAS}

WANG, H.; WANG, S. Research on Industrial Cluster Brand Construction from the Perspective of Cluster Marketing. Marketing Science Innovations and Economic Development, p. 77-82, 2010.

WILK, E.O.; FENSTERSEIFER, J. E. Use of resource-based view in industrial cluster strategic analysis. International Journal of Operations \& Production Management, v. 23, n. 9, p. 9951009, 2003.

ZACCARELLI, S. B. et al. Clusters e Redes de Negócios: uma nova visão para a gestão dos negócios. São Paulo: Atlas, 2008.

\section{APÊNDICE A}

\section{ROTEIRO PARA APROVALE}

- Você enxerga o Vale dos Vinhedos como uma marca do vinho produzido na sua região?

- Você poderia me contar como foi o processo para alcançar os selos de indicação geográfica do Vale dos Vinhedos?

- Na sua opinião qual foi a principal motivação para buscar esses selos?

- Como o reconhecimento do Vale influencia as empresas presentes nele?

- Você percebe que as vinícolas se identificam com a marca "Vale dos Vinhedos"?

- Na sua opinião qual a imagem associada ao Vale dos Vinhedos e como essa imagem é importante economicamente?

- Que ações são tomadas a partir da Aprovale para manter e fortalecer o Vale dos Vinhedos?

Perguntas complementares:

- Poderia me dizer seu nome completo e qual cargo ocupa na Aprovale?

- Há quanto tempo você trabalha na entidade?

\section{APÊNDICE B}

\section{ROTEIRO PARA AS VINÍCOLAS}

- Você acredita que o fato de pertencer ao "Vale dos Vinhedos" te diferencia de outras regiões produtoras de vinho? Em qual sentido?

- Você sente que a marca "Vale dos Vinhedos" representa a sua vinícola? Você se identifica com essa marca?

- Você percebe o "Vale dos Vinhedos" como uma marca coletiva que representa todas as vinícolas e estabelecimentos associados à Aprovale?

- Sua vinícola encontra ou encontrou alguma di- ficuldade para se associar à Aprovale e fazer parte do Vale dos Vinhedos?

- Em geral você acredita que as vinícolas da região preferem ser reconhecidas por fazerem parte do Vale dos Vinhedos ou por sua marca própria?

- Você acha que a marca do Vale dos Vinhedos se sobressai às marcas das vinícolas?

- Vocês (vinícolas e outros estabelecimentos da região) realizam atividades conjuntas para trabalhar pela marca e pela reputação do Vale dos Vinhedos? Poderia me dar exemplos? 


\section{APÊNDICE B}

- O que a marca "Vale dos Vinhedos" significa para você?

Perguntas complementares:

- Poderia me dizer seu nome completo e qual o cargo ocupa na vinícola?
- Desde quando sua vinícola é associada à APROVALE? O que a levou a se associar?

- Qual foi sua contribuição (ou da sua vinícola) na criação da APROVALE? 